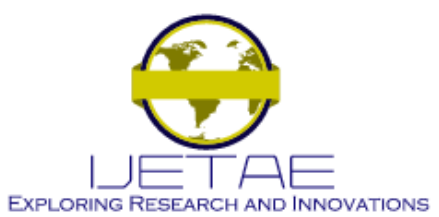

International Journal of Emerging Technology and Advanced Engineering

Website: www.ijetae.com (ISSN 2250-2459, ISO 9001:2008 Certified Journal, Volume 3, Issue 12, December 2013)

\title{
Improved DTC using Three-level Inverter topology for Wind Power Applications
}

\author{
Rosemary Chacko ${ }^{1}$, Shanifa Beevi $\mathrm{S}^{2}$, Dr A. Amar Dutt ${ }^{3}$ \\ Electrical Engineering Department, Rajiv Gandhi Institute of Technology, Kottayam.
}

\begin{abstract}
A DTC technique using NPC three level inverter fed induction motor is presented in this paper. In order to utilize the weak wind irrespective of the required constant angular velocity, a modified DTC with NPC topology can be used. Compared to the conventional DTC, this three level inverter DTC topology provides better dynamic performance with reduced torque ripple. Results obtained by using a versatile simulation package, SIMULINK/MATLAB, for demonstrating the NPC three level Inverter fed Induction motor with Direct Torque Control proves the effectiveness of the proposed topology.
\end{abstract}

Keywords-Direct Torque Control (DTC), hysteresis controller, induction motor drive, Neutral Point Clamped (NPC), three level inverter, torque ripple.

\section{INTRODUCTION}

In most of the wind power applications, the generators used work at constant angular velocity. For increasing the effective utilization of the wind power, the weak winds also need to be consumed even at low frequencies. This can be done using the three-level NPC inverter fed induction motor drive with direct torque control. This control ensures fast dynamic response even at low frequencies [3]. The NPC inverter is one of the most commonly used multilevel inverter topology for driving induction motor at high power applications. This type of control here utilizes a switching table based on torque and flux hysteresis controllers. Unlike in conventional DTC with two- level inverter, here in three-level DTC, 24 voltage vectors are used.

In this paper, the basics of DTC with three-level inverter on Induction motor are discussed. This can be extended for direct torque control of induction generator for wind power applications. Later in this paper, in order to minimize the neutral point voltage unbalance problem, a voltage balancing algorithm is adopted. Simulation results of this control technique have been shown which clearly shows that the ripple content is reduced in torque and flux.

\section{DiRECT TORQue CONTROL OF THREE-LEVEL INVERTER FED DRIVE}

\section{A. Direct torque Control}

In modern automated systems, there are two competing control strategies for ac motors i.e. field oriented control (vector control) and direct torque control (DTC). Nearly 30-32 years ago, in 1971, F.Blaschke presented the paper on field oriented control (FOC) for induction motor control.
Thirteen years later, a new control technique of induction motors was developed and presented by I.Takahashi, as direct torque control (DTC). The name direct torque control is derived from the fact that, on the basis of the errors between the reference and the estimated values of torque and flux, it is possible to control the inverter states directly in order to reduce the torque and flux errors within the prefixed band (hysteresis band) limits [5].

Unlike FOC, DTC does not require any coordinate transformation, current regulator and PWM signals. In spite of its simplicity, DTC allows a good torque control in steady-state and transient operating conditions. The problem is to quantify how good the torque control is with respect to FOC. In addition, DTC controller is very little sensible to the parameters detuning in comparison with FOC.

The block diagram of DTC drive is shown in figure 1 . It consists of closed loop control of speed and flux. The speed regulator consists of a PI controller which processes the speed error obtained as the difference between the actual and reference speeds and generates reference torque. The actual torque and flux are estimated using the stator currents and voltage [1].

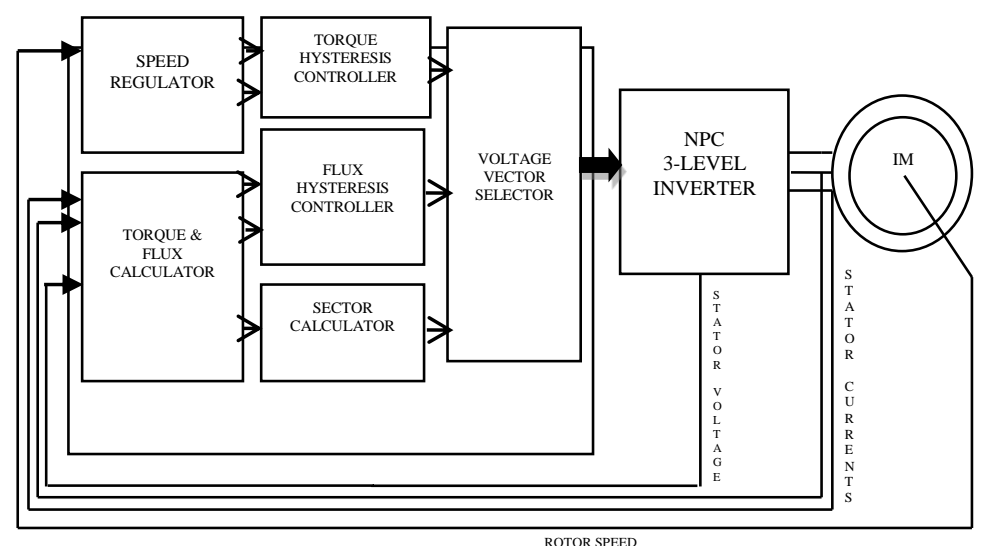

Fig.1. Basic DTC with 3-level inverter configuration

$$
\begin{gathered}
\varphi_{s d}=\int\left(V_{s d}-R_{s} i_{s d}\right) d t \\
\varphi_{s q}=\int\left(V_{s q}-R_{s} i_{s q}\right) d t \\
T_{e}=\frac{3}{2} \frac{P}{2}\left(\varphi_{s d} i_{s q}-\varphi_{s q} i_{s d}\right)
\end{gathered}
$$




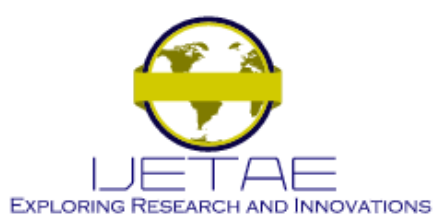

International Journal of Emerging Technology and Advanced Engineering

\section{Website: www.ijetae.com (ISSN 2250-2459, ISO 9001:2008 Certified Journal, Volume 3, Issue 12, December 2013)}

The angular position of the stator flux vector is required to determine the appropriate voltage vector to be selected for switching of inverter switches. Thus the angle can be calculated as:

$$
\theta=\frac{\varphi_{s d}}{\varphi_{s q}}
$$

The torque hysteresis controller used here is a 4-level hysteresis controller. The torque error obtained as the difference between the reference and actual torques can be $2,1,-1,2$.

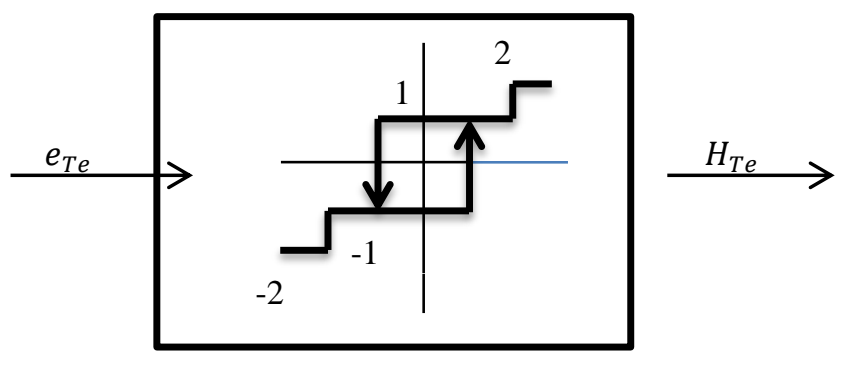

Fig.2 4-level torque hysteresis controller

The output of the torque hysteresis controller, $H_{T e}$, as shown in fig 2 , can be either 2(-2) or 1(-1), depending upon the positive(negative)value of the torque error. If the value of error is within the hysteresis band, then $H_{T e}$ will be $1(-1)$.

The flux hysteresis controller used is a two-level hysteresis controller. The flux error obtained as the difference between the reference and actual fluxes can be 1 or -1 .

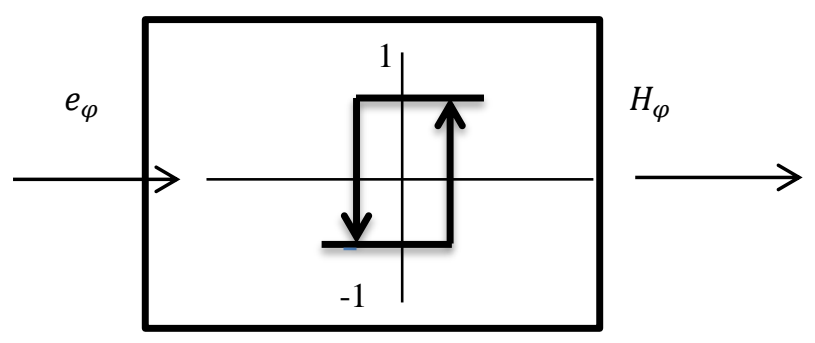

Fig. 3 2-level flux hysteresis controller

The output of the flux hysteresis controller, $H_{\varphi}$, as shown in fig 3 , can be 1 or -1 , depending upon the value of flux error; if the flux error is positive, $H_{\varphi}$ is 1 and if the flux error is negative, $H_{\varphi}$ is -1 .

The voltage vector plane is divided into six sectors. The sector calculator block determines the current stator flux vector position. Depending upon the stator flux vector position and the errors from torque and flux hysteresis controllers, an appropriate voltage vector is selected from the switching table.

\section{B. Neutral Point Clamped three-level Inverter}

Recently, there is a growing demand for high power conversion systems with high output voltage and low harmonics.

Since the multilevel inverters have many advantages, including high voltage capability with the same switching devices, higher quality output voltages and currents, they have been receiving much attention in high power applications [6]. Many multilevel topologies have been proposed, and one of the most popular one is the neutral point clamped (NPC) three level inverter. Fig. 4 shows the NPC three-level inverter topology. Each capacitors, $\mathrm{C}^{+}$and $\mathrm{C}^{-}$, are pre-charged to $\mathrm{E}$ volts. The voltage of terminal ' $a$ ' with respect to neutral point $O$ is $E$ volts when the top switches are turned on. When the bottom switches are turned on, the voltage of terminal ' $a$ ' with respect to $\mathrm{O}$ is $-\mathrm{E}$. When the middle two switches in a phase leg are turned on, the terminal ' $a$ ' is connected to neutral point $\mathrm{O}$ through the clamping diodes.

Table 1 shows the operating status of switches in a NPC three-level inverter. The operation of each phase leg in an inverter can be represented by three switching states [P], [N], [O].

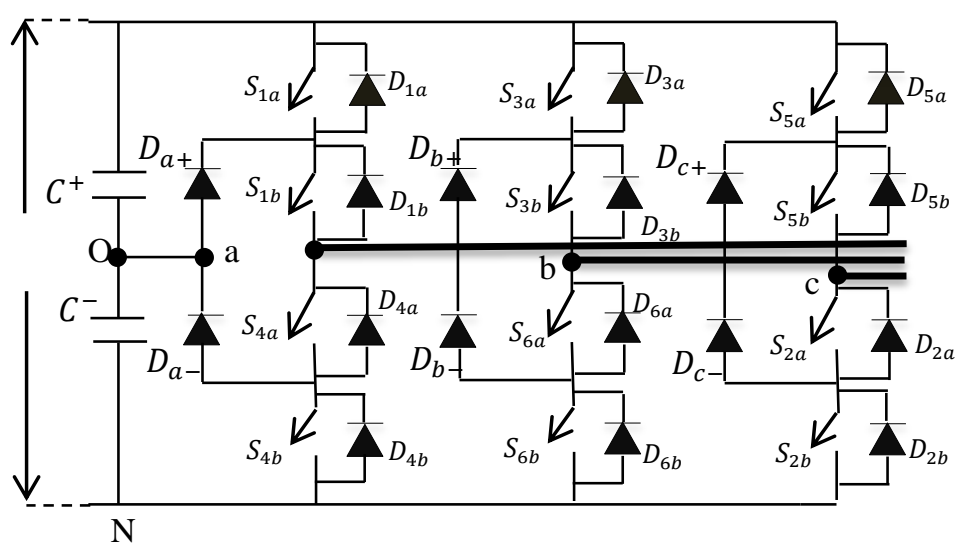

Fig. 4 NPC three-level inverter

TABLE 1

SWITCHING STATES

\begin{tabular}{|c|c|c|c|c|c|}
\hline \multirow{2}{*}{$\begin{array}{c}\text { Switching } \\
\text { State }\end{array}$} & \multicolumn{4}{|c|}{ Device Switching States(Phase } & Terminal \\
Voltage \\
\cline { 2 - 5 } & $S_{1 a}$ & $S_{1 b}$ & $S_{4 a}$ & $S_{4 b}$ & \\
\hline $\mathrm{P}$ & On & On & Off & Off & E \\
\hline O & Off & On & On & Off & 0 \\
\hline $\mathrm{N}$ & Off & Off & On & On & -E \\
\hline
\end{tabular}

Considering an NPC three-level inverter, there are 27 possible switching states, which corresponds to 19 voltage vectors as shown in fig. 5 . Here the whole voltage vector plane is divided into 12 sectors. 


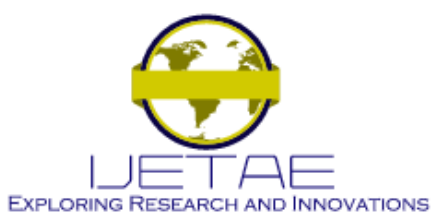

International Journal of Emerging Technology and Advanced Engineering Website: www.ijetae.com (ISSN 2250-2459, ISO 9001:2008 Certified Journal, Volume 3, Issue 12, December 2013)

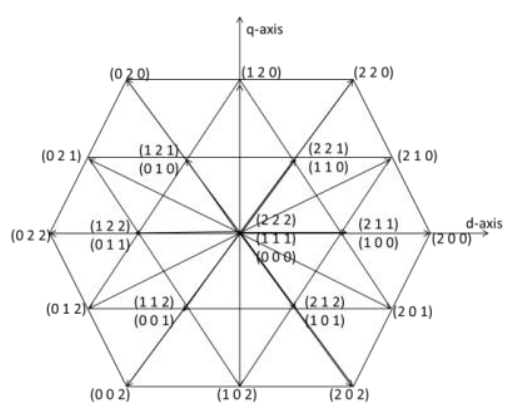

Fig. 5 Space vector diagram of a 3-level NPC inverter

Based on the magnitude of the voltage vectors, they are classified into four categories.

a) Zero vectors: whose magnitude is zero and is represented as $V_{o}$. They are $[P P P],[N N N]$ and $[O O$ $O]$.

b) Small vectors: whose magnitude is $\frac{V_{d}}{3}$ and are represented as $V_{1}$ to $V_{6}$.

c) Medium vectors: whose magnitude is $\frac{\sqrt{3} V_{d}}{3}$ and are represented as $V_{7}$ to $V_{12}$.

d) Large vectors: whose magnitude is $\frac{2 V_{d}}{3}$ and are represnted as $V_{13}$ to $V_{18}$.

\section{Voltage Balancing Algorithm}

One of the major drawbacks encountered in a neutral point clamped inverter is the neutral point voltage unbalancing. As the DC link voltage is divided by capacitors, the current flowing out or into the neutral point can result in the unbalance of neutral point. Neutral point voltage unbalance increases the output voltage harmonics and may shift the output voltage to an unacceptable level, and may damage the switching devices and filter capacitors.

For voltage balancing at the neutral point only 12 active voltage vectors are used as shown in fig.6. It uses only small and large vectors for switching. As far as zero vectors are considered, if they were used, it would not be possible to magnetize the motor at zero speed at no load, so they are not used [2]. As the large vectors cause the machine terminals to get connected either to point $\mathrm{P}$ or $\mathrm{N}$, there is no voltage ripple at point $\mathrm{O}$. Thus there is no power loss at terminal $\mathrm{O}$ due to large vectors. Both the medium and small vectors are causing the voltage unbalancing at neutral point as they inject current into or draw from the neutral point [4].

Here in this algorithm, as only small and high vectors are employed for balancing the voltage at neutral point, medium vectors are not considered.
In case of small vectors, each configuration can be obtained with two different switching patterns, which have opposite effects on neutral point in steady state.

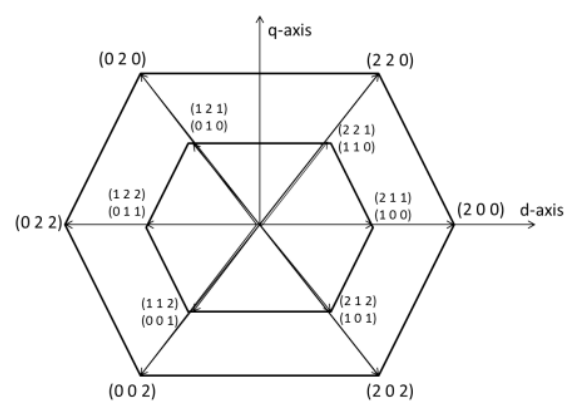

Fig. 6 Proposed space vector diagram

If in one switching pattern, the current is injected into the neutral point, in the other switching pattern, the current is drawn from the neutral point; for example (2 2 1) and (lll 10 ), have opposite effects on the voltage unbalance of the neutral point in steady-state. Therefore they can be employed to balance the neutral point voltage. Thus the voltage unbalancing at neutral point due to the small vectors are compensated and are used for voltage balancing.

These 12 active voltage vectors are categorized into two groups on the basis of the voltage level as shown in the table 2 .

TABLE 2

VOLTAGE VECTORS FOR NEUTRAL POINT BALANCING

\begin{tabular}{|l|c|c|c|c|c|c|}
\hline $\begin{array}{l}\text { Voltage } \\
\text { level }\end{array}$ & $V_{1}$ & $V_{2}$ & $V_{3}$ & $V_{4}$ & $V_{5}$ & $V_{6}$ \\
\hline HIGH & $\left(\begin{array}{llll}2 & 0 & 0\end{array}\right)$ & $\left(\begin{array}{llll}2 & 2 & 0\end{array}\right)$ & $\left(\begin{array}{llll}0 & 2 & 0\end{array}\right)$ & $\left(\begin{array}{llll}0 & 2 & 2\end{array}\right)$ & $\left(\begin{array}{llll}0 & 0 & 2\end{array}\right)$ & $\left(\begin{array}{lll}2 & 0 & 2\end{array}\right)$ \\
\hline & $\left(\begin{array}{lll}2 & 1 & 1\end{array}\right)$ & $\left(\begin{array}{llll}2 & 2 & 1\end{array}\right)$ & $\left(\begin{array}{llll}1 & 2 & 1\end{array}\right)$ & $\left(\begin{array}{llll}1 & 2 & 2\end{array}\right)$ & $\left(\begin{array}{llll}1 & 1 & 2\end{array}\right)$ & $\left(\begin{array}{lll}2 & 1 & 2\end{array}\right)$ \\
LOW & $\left(\begin{array}{llll}1 & 0 & 0\end{array}\right)$ & $\left(\begin{array}{llll}1 & 1 & 0\end{array}\right)$ & $\left(\begin{array}{llll}0 & 1 & 0\end{array}\right)$ & $\left(\begin{array}{llll}0 & 1 & 1\end{array}\right)$ & $\left(\begin{array}{llll}0 & 0 & 1\end{array}\right)$ & $\left(\begin{array}{llll}1 & 0 & 1\end{array}\right)$ \\
\hline
\end{tabular}

Here, when the voltage level is LOW, there are two possible combinations. Depending upon the torque and flux errors obtained from the hysteresis controllers, an appropriate voltage vector is selected. The voltage vector selected can be HIGH or LOW, depending upon the nature of error. This is clearly shown in table 3.

TABLE 3

CONTROL STRATEGY

\begin{tabular}{|c|c|c|c|c|c|c|c|c|}
\hline$T_{e}, \varphi_{e}$ & \multicolumn{3}{|c|}{ 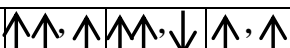 } & \multicolumn{2}{|c|}{$\uparrow, \downarrow \downarrow, \uparrow$} & & & \\
\hline Voltage & LOW & LOW & HIGH & HIGH & HIGH & HIGH & LOW & LOW \\
\hline vector & $V_{i+1}$ & $V_{i+2}$ & $V_{i+1}$ & $V_{i+2}$ & $V_{i-1}$ & $V_{i-2}$ & $V_{i-1}$ & $V_{i-2}$ \\
\hline
\end{tabular}

(Double up arrow=strong increase, Double down arrow= strong decrease, up arrow=increase, down arrow=decrease) 


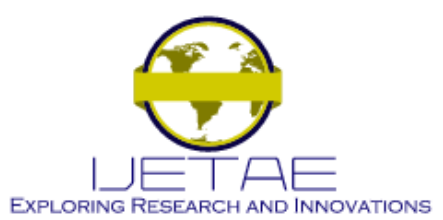

International Journal of Emerging Technology and Advanced Engineering

Website: www.ijetae.com (ISSN 2250-2459, ISO 9001:2008 Certified Journal, Volume 3, Issue 12, December 2013)

III. Simulation AND RESUlts

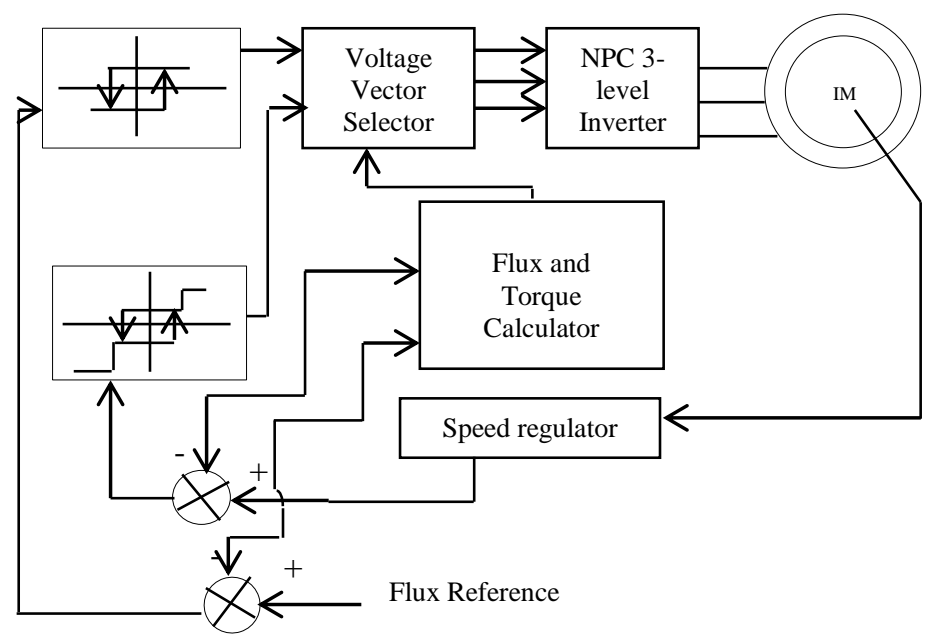

Fig. 7 Block Diagram of DTC with 3-level inverter

Fig. 7 shows the block diagram of direct torque control with three-level inverter simulated on induction motor. In order to show the effectiveness of the control strategy, the simulation is carried out on induction motor. The control scheme is simulated with Matlab/SIMULINK, which is the most powerful and popular tool for simulation.

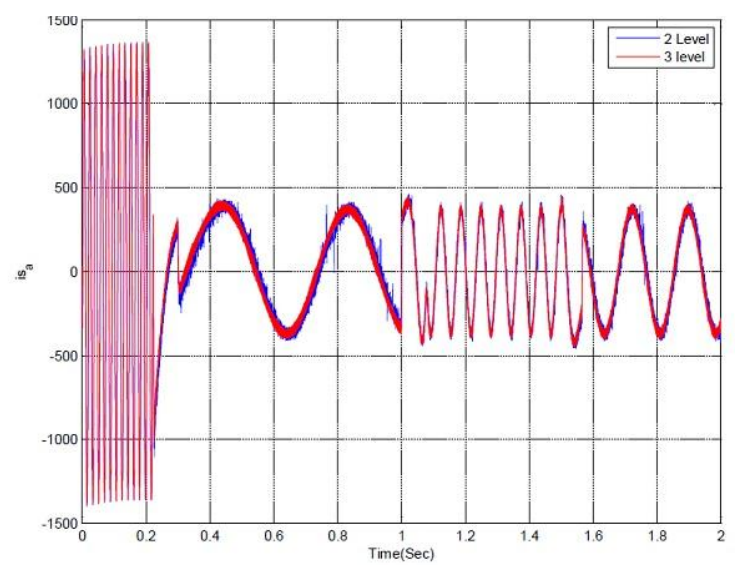

Fig. 8 Stator current waveform

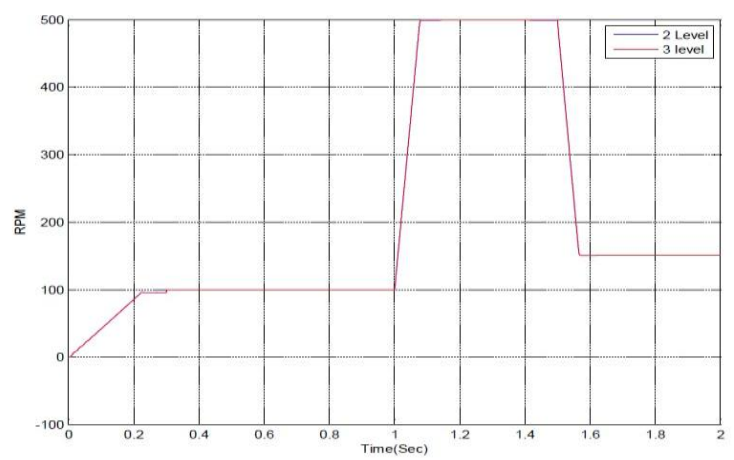

Fig. 9 Rotor speed

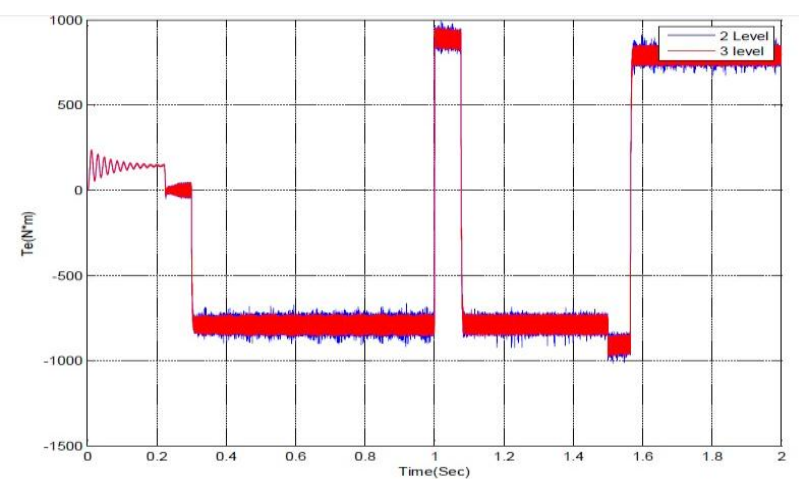

Fig. 10 Torque

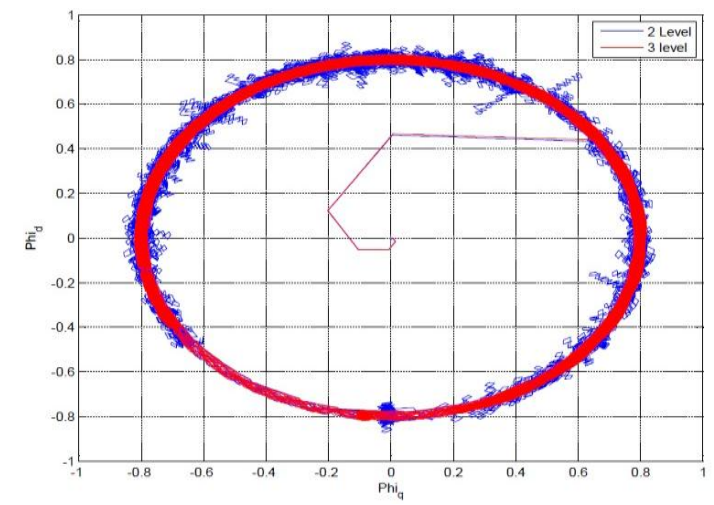

Fig.11 Stator flux

The induction motor used for simulation has a nameplate reading of three phase $460 \mathrm{~V} \mathrm{ac}, 200 \mathrm{HP}$, rated speed of $1500 \mathrm{rpm}$ and reference torque of $0.8 \mathrm{Nm}$. Fig. 8 shows the stator current of the DTC driven induction motor drive. Fig. 9 shows the rotor speed. The reference speed given was $100 \mathrm{rpm}$ for 1 second. Later it changes to $500 \mathrm{rpm}$ for 0.5 second (from $1 \mathrm{sec}$ to $1.5 \mathrm{sec}$, speed is $500 \mathrm{rpm}$ ). At 1.5 second, speed changes to $150 \mathrm{rpm}$.

Fig.10 shows the torque of the induction motor. The load torque applied is zero for first 0.3 second and it changes to $-792 \mathrm{Nm}$ at 0.3 second. At 1.5 second, load torque changes to $792 \mathrm{Nm}$. The mechanical speed track the reference values imposed and corresponding to different values of rotor speed. Fig.11 shows the stator $\mathrm{d}-\mathrm{q}$ flux locus, which is uniform.

\section{CONCLUSION}

This paper presents a very simple implementation of direct torque control of an induction motor drive with three-level inverter (neutral point clamped topology) and voltage balancing algorithm. This work is an extension of the conventional DTC with two-level inverter. The results show that the induction motor with direct torque control using three-level inverter gives reduced torque ripple and smooth flux locus. Thus it can be concluded that the DTC method when applied to doubly fed induction generator for wind system contribute to improvement of system response parameters. 


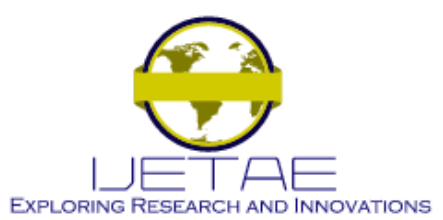

International Journal of Emerging Technology and Advanced Engineering

Website: www.ijetae.com (ISSN 2250-2459, ISO 9001:2008 Certified Journal, Volume 3, Issue 12, December 2013)

\section{REFERENCES}

[1] Dipti H. Ganatra, Saurabh N. Pandya, "Torque Ripple Minimization in Direct Torque Control based Induction Motor Drive Using Multilevel Inverter", IEEE Students' Conference on Electrical, Electronics and Computer Science,2012.

[2] M. Cirrincione, M. Pucci, G. Vitale, "A DTC Algorithm for Induction Motor Drives with 3-level Diode-Clamped Inverters", J.Electrical Systems 1-4(2005):17-32.

[3] K. Kulikowski, A. Sikorski, "Efficiency improvement due to direct torque and flux three levels three areas control method applied to small hydroelctric power plant", Bulletin of the Polish academy of sciences, Vol. 59, No.4, 2011.
[4] Kyo-Beum Lee, Joong-Ho Song, Ick Choy, Ji-Yoon Yoo, ’Torque ripple Reduction in DTC of Induction Motor Driven by ThreeLevel Inverter with Low Switching Frequency ", IEEE Transactions on Power Electronics, Vol.17, No.2, March 2002.

[5] I. Takahashi and T. Noguchi, "A new quick-response and high efficiency control strategy of an induction motor", IEEE Trans. Ind.Appl., vol. IA-22, no. 5, pp. 820-827, Sept. 1986.

[6] B. K Bose ," Power Electronics handbook", Academic Press, Chapter 14 